\title{
The Epistemic Significance of Religious Disagreements: Cases of Unconfirmed Superiority Disagreements
}

\author{
Frederick $\mathrm{Choo}^{1}$ (10
}

Published online: 14 November 2018

๑) Springer Nature B.V. 2018

\begin{abstract}
Religious disagreements are widespread. Some philosophers have argued that religious disagreements call for religious skepticism, or a revision of one's religious beliefs. In order to figure out the epistemic significance of religious disagreements, two questions need to be answered. First, what kind of disagreements are religious disagreements? Second, how should one respond to such disagreements? In this paper, I argue that many religious disagreements are cases of unconfirmed superiority disagreements, where parties have good reason to think they are not epistemic peers, yet they lack good reason to determine who is superior. Such disagreements have been left relatively unexplored. I then argue that in cases of unconfirmed superiority disagreements, disputants can remain relatively steadfast in holding to their beliefs. Hence, we can remain relatively steadfast in our beliefs in such cases of religious disagreements.
\end{abstract}

Keywords Religious disagreement $\cdot$ Epistemology of disagreement $\cdot$ Peer disagreement $\cdot$ Peerhood

\section{Introduction}

Religious disagreements are widespread. Some philosophers have argued that religious disagreements call for religious skepticism, or a revision of one's religious beliefs. ${ }^{1}$ Others have argued against such skeptical arguments. ${ }^{2}$ In order to figure out the epistemic significance of religious disagreements, two questions need to be answered. First, what kind of disagreements are religious disagreements? Second, how should one respond to such disagreements?

Three main positions have been taken in the literature to address the first question. The first position holds that religious disagreements are peer disagreements, where parties have good reason to take each other as epistemic peers. ${ }^{3}$ Philosophers holding this position either argue that peer disagreement requires some amount of skepticism or argue that we should remain steadfast in our beliefs. The second position holds that in religious disagreements, parties are justified in taking themselves as superiors. ${ }^{4}$ In such a case, parties can remain steadfast in their beliefs. The third position holds that religious disagreements are unconfirmed peer

Frederick Choo

fcwy1@ hotmail.com

1 Nanyang Technological University, Singapore, Singapore disagreements, where there is no good reason to take disputants as an epistemic peer, inferior or superior, but there is no good reason to dismiss disputants as peers either. ${ }^{5}$ As in cases of peer disagreement, philosophers who take up this position differ in whether such disagreement requires revision of our beliefs.

In this paper, I argue for a fourth position. I argue that many religious disagreements are cases of unconfirmed superiority disagreements, where parties have good reason to think they are not epistemic peers, yet they lack good reason to determine who is superior. This differs from unconfirmed peer disagreements in that disputants have reason to think they are not peers. This I hope opens up discussion of how we should respond to such cases of disagreements. I then set out my own position: in cases of unconfirmed superiority, disputants can remain relatively steadfast in holding to their beliefs. Hence, we can remain relatively steadfast in our beliefs in such cases of religious disagreements.

\footnotetext{
${ }^{1}$ See for example Feldman (2007), Kraft (2012) and Matheson (2017).

2 See for example Bergmann (2015), Bogardus (2013), DePoe (2011), Pittard (2014) and King (2012).

${ }^{3}$ See for example Frances (2015), Kraft (2012), Lackey (2014) and Matheson (2017).

${ }^{4}$ See for example Bergmann (2015), Bogardus (2013), DePoe (2011), Oppy (2010) and Pittard (2014).

${ }^{5}$ See for example Sherman (2015) and arguably Feldman (2007).
} 
In Sect. 2, I clarify the idea of epistemic peerhood I am working with. I argue that we should understand peerhood in terms of being equal in one's total epistemic position. In Sect. 3, I lay out two main standards to evaluate peerhood. In Sect. 4, I apply the two standards to religious disagreements. I argue that many religious disagreements are cases of unconfirmed superiority disagreements. In Sect. 5, I consider two views on the epistemic significance of unconfirmed peer disagreements. In Sect. 6, I draw from the discussion in Sect. 5 and argue that disputants can remain relatively steadfast in holding to their belief in cases of unconfirmed superiority.

\section{The Idea of Epistemic Peerhood}

Most of the literature on the epistemology of disagreement focuses on peer disagreement (Gelfert 2011). Peer disagreement occurs when one faces a disagreement with a disputant whom one has good reason to take as an epistemic peer. ${ }^{6}$ Some think that one should suspend belief in such cases. ${ }^{7}$ Others think one should assign equal weight to both views and conciliate. ${ }^{8}$ Still, others think that one can remain steadfast in one's belief when certain conditions are satisfied (such as having an error theory about the opposing position or having high antecedent justification for one's belief). ${ }^{9}$ These views all rely on the idea of epistemic peerhood. There are many conceptions and definitions of epistemic peerhood. In this section, I will argue that we should understand peerhood in terms of one's total epistemic position.

Roughly, two things are important when it comes to one's total epistemic position. The first has to do with evidential possession and the second has to do with evidential processing. ${ }^{10}$ Regarding the first, what is relevant is what evidence one possesses. Regarding the second, what is relevant would be methodologies, epistemic virtues and epistemic ability. When it comes to peerhood, some thinkers hold that epistemic peers are those who both possess the same evidence and process evidence the same way. Catherine Elgin for example says that epistemic peers must have the "same evidence, reasoning abilities, training, and background

\footnotetext{
${ }^{6}$ Some take peer disagreement to be cases where disputants are in actual fact peers, or cases where one takes the other to be a peer, or cases where one justifiably takes one as a peer. I take peer disagreement to be cases in which one has reason to take the other party as a peer.

${ }^{7}$ See for example Feldman (2007).

8 See for example Christensen (2011), Elga (2007), Matheson (2017).

9 See for example Bergmann (2009, 2015), Kelly (2005), Lackey (2010).

10 See for example Kelly (2005, pp. 174-175), Matheson (2015, p. 22), King (2012, p. 252)
}

assumptions" (2010, p. 53). Sameness is important. Other thinkers however think sameness is not necessary. Instead, what is important is equality. For example, when Thomas Kelly talks about epistemic peerhood, he says "two individuals are epistemic peers with respect to some question if and only if they satisfy the following two conditions: (i) they are equals with respect to their familiarity with the evidence and arguments which bear on that question, and (ii) they are equals with respect to general epistemic virtues such as intelligence, thoughtfulness, and freedom from bias" (2005, pp. 174-175). Jonathan Matheson supports this idea as he points out that one can achieve equality in evidential possession by "having distinct, but equally good, bodies of evidence" (2015, p. 22). One can also achieve equality in evidential processing as long as "the likelihood of their processing the evidence correctly is equally high," even if they process the evidence differently (2015, p. 22). For example, people who use different methods to solve a math sum can be epistemic peers if the methods are equally reliable. Matheson further thinks that one may make up for lack of evidence by being better at processing evidence, or vice versa, making both parties equally likely to be right $(2015$, p. 23$)$. What is important for these thinkers is equality instead of sameness.

I think that we should take epistemic peers as those who are equal in their total epistemic positions. ${ }^{11}$ This is because such an understanding of peerhood seems to be the driving force behind the different principles and arguments in the literature. For example, conciliationists think that one should give equal weight to one's disputant in cases where both possess the same evidence and same dispositions because having the same evidence and dispositions makes both equally likely to be correct in that scenario. ${ }^{12}$ The intuition many conciliationists seem to have is that I should give my disputant's view equal weight if I take the disputant to be in an equal epistemic position, since both of us are as likely to be right. ${ }^{13}$ Hence, we should take epistemic peers as those who are equal in their total epistemic positions.

\footnotetext{
11 To note, there may also be circumstantial factors that causes one not to assess the evidence reliably in a particular dispute. For example, one may be overly tired on a particular occasion when weighing the evidence. Hence, what is required is being in equal epistemic positions in the particular dispute, and not just merely generally (Matheson 2015, p. 23).

12 See for example Christensen (2011), Elga (2007), Matheson (2015).

${ }^{13}$ Elga (2007) takes peer disagreement to occur when both parties are equally likely to be right in the particular occasion.
} 


\section{Assessing Peerhood}

With this idea of peerhood, we need to ask when one has good reason to take a disputant as a peer or not. This is because some philosophers have pointed out that in many actual cases of disagreement, we may lack good reason to take others as epistemic peers. ${ }^{14}$ If we lack good reason to take others as epistemic peers, then the principles and arguments in the literature-which in general simply stipulate peerhood and focus on examining its epistemic implications-lose much of their relevance. Given this, what I think has not been adequately discussed is how we should assess whether someone is a peer (or not a peer). Below, I examine two main ways of doing so.

The first standard of assessment is based on wide-ranging agreement and disagreement with one's disputant in regards to the disputed proposition. Adam Elga's idea is that if we disagree on a wide-ranging number of issues, then we have good reason to think we are not peers (2007, pp. 492-496). Elga raises an example as follows. If Ann and Beth disagree on whether abortion is permissible, they may have further discussed "whether human beings have souls, whether it is permissible to withhold treatment from certain terminally ill infants, and whether rights figure prominently in a correct ethical theory" (Elga 2007, p. 493) If they disagree on all these issues, Ann will have good reason to think Beth is not a peer when it comes to abortion, even if Beth seems "as thoughtful, well-informed, quick-witted, and so on" (Elga 2007, p. 493) So Elga's idea is that wide-ranging disagreement with one's disputant in regards to the disputed proposition gives one good reason not to take the disputant as a peer.

If wide-ranging disagreement gives us reason to dismiss a disputant as a peer, how about wide-ranging agreement? I suggest that we have good reason to think one's disputant is at least a peer if the disputant largely agrees with you regarding other propositions in the related field (or regarding other relevant propositions). ${ }^{15}$ For example, suppose my friend and I disagree on a math question on a test. We then compare all the other answers to other math questions we have done on the test and they are the same. It seems that the wide-ranging agreement with my friend gives me good reason to think he is at least equally likely to be right regarding the disputed question.

Going back to Elga's case, what happens if there is wideranging disagreement? I do think that Elga is right in saying that wide-ranging disagreement gives one good reason to dismiss a disputant as a peer. However, Elga further thinks

\footnotetext{
${ }^{14}$ See for example King (2012), Elga (2007, p. 492) and Lackey (2010, pp. 311-312).

15 To note, the disputant's agreement must be independent of your assessment.
}

that this justifies a person in taking oneself as epistemically superior (2007, p. 493). Contra Elga, I think wide-ranging disagreement does not give one good reason to take oneself as epistemically superior (or inferior for that matter). Suppose my math teacher marks my paper and disagrees with many of my answers. Surely, this provides no reason to think she is epistemically inferior. Hence, wide-ranging disagreement only provides some reason to doubt that one's disputant is a peer but not give us reason to take ourselves as epistemically superior.

A second standard of assessment is based on the relevant credibility-conferring features (i.e. evidential possession and processing). ${ }^{16}$ First, one must ask what the relevant credibility-conferring features are in regard to the disputed case. For example, in regards to evidential possession, one might ask what is considered relevant evidence to the dispute. In regards to evidential processing, one may ask what dispositions or virtues would make one reliable in this case. One might also have an error theory to dismiss a disputant's evidence as misleading or unreliable, or to think that one has processed the evidence unreliably. ${ }^{17}$ Second, one must be able to compare oneself with one's disputant in terms of both evidential possession and processing. If a disputant's overall set of the relevant credibility-conferring features is equally good as one's own set, then one should take a disputant as a peer. The advantage of this method of assessing peerhood is that even if one is not a peer, we can still determine whether we should take a disputant as epistemically superior or inferior, and to what extent. For example, if someone's overall set is only slightly inferior to mine, then I should still assign some degree of trust to him. If someone's overall set is much more inferior, then I might assign very little trust or even none.

Regarding the second standard of assessment, some worries may arise. In many cases, it may be hard to answer exactly what credibility-conferring features are relevant. Another difficulty is in making the comparison with one's disputant. Often, it is hard to judge whether one's disputants have these credibility-conferring features and to what extent. It may also be hard to judge oneself objectively. For example, it is difficult to assess how careful our disputant is compared to us when answering a mathematical question.

A way to overcome these difficulties is to look at one's track record, where a track record may consist of various things like testimony, institutional certification, having been right in previous disagreements, and so forth. This may tell

\footnotetext{
16 This term comes from Sherman (2015, p. 427).

17 An error theory is a theory one has about why others are in error. For example, if I meet someone who is drinking a lot of alcohol and disagrees with me on an intellectual issue, I have an error theory, namely that the alcohol he drinks causes cognitive malfunction.
} 
us if our disputant has the relevant credibility-conferring features without having to identify and assess the specific features. To illustrate, suppose a stranger and I disagree on a math question. We both take out our school results and find that both of us have gotten an A on our past few math exams. His track record gives me reason to take him as a peer even though I cannot directly know specifics such as how careful he is when doing math problems or how many math textbooks he has read. I do not need to identify the list of evidence and dispositions followed by attempting to make a comparison. I can just assess him using his track record.

The two standards of assessments above can each provide reasons for taking someone as a peer, or dismissing someone as a peer. Thus, even if I cannot assess a disputant's track record or his credibility-conferring features directly, I may know that we disagree on a wide-ranging set of issues related to the disputed proposition. So the first standard gives me reason to take him as a non-peer. Likewise, there may be times where the first standard of assessment is unavailable and the second standard can be used. One may worry that at times they could conflict. For example, a disputant may have an equally good track record as you and even seem to share the same credibility-conferring features. However, both of you disagree on a wide-ranging number of issues. Hence, the second standard gives you a reason to take them as a peer while the first standard gives you reason to dismiss them as a peer. The issue of how we should balance the standards is an interesting question; this however would have to be another topic for another paper. For now, it would suffice to say that both standards can each provide reasons for taking one as a peer or dismissing one as a peer.

\section{What Kind of Disagreements are Religious Disagreements?}

With these two standards of determining if one is a peer, we can now apply them to religious disagreements. To recall, there are three main positions that have been taken in the literature. The first position holds that religious disagreements are peer disagreements. ${ }^{18}$ The second holds that in religious disagreements, parties are justified in taking themselves as superior. ${ }^{19}$ The third holds that religious disagreements are unconfirmed peer disagreements, where there is no good reason to take disputants as epistemic peers, inferiors or

\footnotetext{
18 See for example Frances (2015), Kraft (2012), Lackey (2014) and Matheson (2017).

19 See for example Bergmann (2015), Bogardus (2013), DePoe (2011), Oppy (2010) and Pittard (2014)
}

superiors, but there is also no good reason to think disputants are not peers either. ${ }^{20}$

In this section, I will argue that many religious disagreements are instead best understood as cases of unconfirmed superiority disagreement. Such a case is similar to unconfirmed peer disagreements, where parties lack good reason to take disputants as an epistemic peer, inferior, or superior. However, the difference is that in unconfirmed superiority disagreements, there is good reason to think one's disputant is not a peer. In unconfirmed superiority disagreements, one party is superior, though disputants lack good reason indicating who it is.

The cases of religious disagreements I have in mind are of three types:

(A) Disagreements about God's existence (between theists and atheists).

(B) Disagreement about which religion is right (between religions).

(C) Disagreement about religious propositions within one's own religion.

There are of course other types of religious disagreements, such as a disagreement between an agnostic and an atheist for example. I will however only focus on the three types of religious disagreements above. Also, in arguing that many of these types of disagreements are cases of unconfirmed superiority, I do not mean to say that all disagreements of the above types are cases of unconfirmed superiority. Within these three types of religious disagreements, there are surely cases which are not unconfirmed superiority disagreements and a different response might be called for in those cases.

Let's start with the first standard of assessing peerhood based on wide-ranging agreement and disagreement with one's disputant. First, consider (A). Between a theist and atheist, they will not only disagree on whether God exists, but on whether heaven exists, whether we should pray, and so forth. There are few religious propositions that I think the theist and atheist would likely agree upon. ${ }^{21}$ Next, consider (B). Between (for instance) Christian theists and Muslim theists, they will disagree on whether Jesus is God, whether God is a Trinity, whether the Bible has been corrupted, conditions for salvation and so forth. Even for (C), there is often wide-ranging disagreement. For example, two Christian theologians who disagree on whether we have libertarian freewill might disagree on the doctrine of original sin, whether Christ only died for the elect, the extent and effect

\footnotetext{
${ }^{20}$ See for example Sherman (2015) and arguably Feldman (2007).

21 They might for example agree on propositions with a logical disjunction such as <either God exists or God does not exist>.
} 
of God's grace, and so forth. ${ }^{22}$ The wide-ranging disagreement described above seems plentiful, though more prominent in (A) and (B) and less so in (C). Hence, it seems that in many cases of religious disagreements, there is wide-ranging disagreement with one's disputant regarding many religious propositions. This means that one has reason to doubt that one's disputants are peers in such cases. The wide-ranging disagreement shows that both parties are in different epistemic positions. To further note, as argued above, this does not provide justification for any party to take themselves as epistemically superior. So the first standard of assessment provides some reason to think that many cases of religious disagreements are unconfirmed superiority disagreements.

We may next move to the second standard to assess peerhood. Here, we must first answer what the relevant credibility-conferring features are when it comes to religious propositions. This however is problematic in religious disagreements because disputants disagree on what the relevant credibility-conferring features are. This is easily seen in the diversity of justifications religious people give for their beliefs. Some may say that what is relevant is argumentation, usually in terms of philosophical or scientific arguments. Others may say that one must be devoted to exercising the appropriate meditation techniques. Others say that faith is required to see religious truths. Others say that religious experiences or special Divine revelation is required. So there is disagreement on what the relevant credibility-conferring features are when it comes to assessing religious propositions. Though not as prevalent, this is sometimes even debated within one's own religion. For example, Christian philosophers and theologians debate on the role of faith and reason, on the role of the Holy Spirit, on the use of natural theology, and so on. ${ }^{23}$ Buddhists may disagree on what exactly are the appropriate meditation techniques. Given the disagreements, one cannot just assume that the set of credibility-conferring features one holds to is the right one. Call this the diversity problem. This problem I think plagues both (A) and (B) significantly, and (C) in some cases. ${ }^{24}$

Next, there is also a circularity problem. Can one justify which set of credibility-conferring features is relevant without circularity? First, in many cases, one holds to a certain set of credibility-conferring features only because one

\footnotetext{
$\overline{22}$ This can be seen in the Calvinism versus Arminianism theological debate.

${ }^{23}$ Moser (2010, pp. 142-184) for example rejects natural theology outright, thinking that natural theology provides evidence that is impersonal which is not what we should expect from God.

${ }^{24}$ One reviewer has pointed out that this may further give us reason to dismiss the other party as a peer. The fact that both parties appeal to epistemic methods or standards which the other party find unacceptable seems to hint that they are not peers in regards to the issue at hand.
}

already holds one's own religious position. For example, Buddhists believe that meditation is necessary to be able to see the truths in the Buddhist teachings. However, they believe this only because they already believe those Buddhist teachings in the first place.

Second, the relevant set of credibility-conferring features is dependent on which view is correct. Consider the issue of God's existence. Alvin Plantinga for example argues that if the Christian God exists, then there probably is a faculty that helps us form belief in God under certain circumstances by giving us theistic experiences (2015, pp. $45-56) .{ }^{25}$ So if God exists, then theistic experiences are relevant evidence. Belief in God can be properly basic and not inferred from other propositions. John Pittard further adds that many religious believers could easily read 1 Corinthians 1:18-29 to say "that the possession of wisdom, or at least the possession of wisdom as it is conventionally understood, does not reliably help someone to arrive at the truth regarding God" (2014, pp. 87-91). So if the Christian God exists, philosophical and scientific arguments may be considered irrelevant credibility-conferring features and theistic experiences are highly relevant instead. This view is held by many lay religious believers. Now if such a God does not exist, then another set of credibility-conferring features would be relevant instead. Philosophical and scientific arguments may be considered as highly important while theistic experiences would just be misleading evidence. Hence, which set of credibility-conferring features is relevant depends on which view is correct. This creates a circularity problem. In order to determine what one should believe about God's existence, one must assess what the relevant credibility-conferring features are, but one can only do so depending on whether God exists.

Despite these problems, some philosophers argue that parties can take themselves as epistemically superior in terms of credibility-conferring features. John DePoe for example says that religious believers may each think that their evidence is better than the other's. He says, "Due to the private nature of religious experiences (and their counterfeits), we are not able to compare the evidential quality of different supposed religious experiences" (2011, p. 105). Here, I think DePoe makes a jump. He seems to think that if one cannot compare evidence, then one can take one's own evidence as superior. But why think so? If we cannot make a comparison, then we cannot say if one is superior to the other.

Other philosophers have instead tried to find other reasons to downgrade disputants through error theories. For example, theists may think that atheists are blinded by sin

\footnotetext{
${ }^{25}$ To be precise, Plantinga thinks that the faculty is damaged by sin but under certain conditions, such as the Holy Spirit working in a person, the faculty will function properly.
} 
(Plantinga 2015, pp. 43-44), or just lack religious experience (Frances 2015, p. 187; Bergmann 2015, p. 48), or they fear submission to a higher authority. ${ }^{26}$ Atheists may think that theists suffer from various epistemic weaknesses like social pressures or wishful thinking (Frances 2015, p. 187; Russell 2017). An example of these competing error theories can be found in Bruce Russell's review of Paul Moser's The Elusive God. Russell (2017) says "[Moser] sees evidence and good God-invoking explanations of religious experiences where I see none. No doubt he will attribute this to my spiritual blindness, and that, ultimately, to my selfishness and pridefulness. Of course, I think that his views about theistic evidence and explanation rest on wishful thinking."

I think that the error theories in many cases do not give one good reason to take oneself as epistemically superior. The problem is that these error theories suffer from both the diversity problem and the circularity problem described above. For example, a Christian may believe that an atheist is spiritually blinded by sin because she believes the Bible teaches this. Furthermore, error theories apply not just to the first-order issue of disagreement but also to the other side's error theories. For example, a theist may say that the reason why an atheist holds an error theory against religious believers is the result of the atheist being blinded by sin. The atheist will likewise have an error theoretic explanation of the theist's error theory, and so forth. The upshot of this is that error theories seem to ultimately go nowhere as a way of determining epistemic superiority.

Everything said in this section likewise applies, mutatis mutandis, to disagreements between religions. As with disagreements between theists and atheists, disagreements between adherents of different religions appeal to different religious epistemological views and error theories. For example, the Quran (17, pp. 45-46) seems to talk about Allah blinding unbelievers. Buddhists may likewise claim that non-Buddhists lack proper meditation techniques and hence their minds cannot grasp the ultimate truths of the world. ${ }^{27}$ To sum up, there is difficulty determining what the relevant credibility-conferring features are in cases of disagreement.

What can however be seen is that parties often differ greatly in evidential possession and processing. These asymmetries give us some reason to think that parties are in different epistemic positions. Take for example the following

\footnotetext{
${ }^{26}$ DePoe (2011, pp. 109-110) claims that "many non-Christians have rejected Christianity on the grounds that they want to believe that they are the ultimate authority of their lives." This fear of submitting to God is a cognitive defect. As examples, he cites Thomas Nagel and C. S. Lewis in his pre-Christian state of mind.

27 Thune (2010, p. 720) uses this example when it comes to the Buddhist doctrine of "dependent origination" (which teaches that "everything is a stream of mental activity in constant flux').
}

simple model. Suppose Jane is a typical religious believer with religious experiences but no philosophical training. Meanwhile, Ken is an atheistic philosopher with no religious experiences. Both claim epistemic superiority because they differ on what they think the relevant credibility-conferring features are. If Jane is right about the relevant credibilityconferring features, they are not peers. If Ken is right about the relevant credibility-conferring features, they are not peers. Either way, they are not peers. So regardless of who is right about the relevant credibility-conferring features, both can agree that they are not in equal epistemic positions in either case. Hence, based on the second standard of assessment, there is reason to think that disputants in religious disagreements are not equal in epistemic positions.

What can be learnt from the two standards of assessment is that parties in religious disagreements often have good reason to think that one's disputant is not a peer. Both standards give parties good reasons to dismiss each other as a peer. While parties have good reason to believe that they are in different epistemic positions, it is questionable who is in a better epistemic position. Hence, many religious disagreements are not cases of peer disagreement. Nor are they cases where one can justifiably dismiss one's disputant as epistemically inferior. Nor are they cases of unconfirmed peer disagreement since parties have good reason to think they are not peers. Such religious disagreements are unconfirmed superiority disagreements.

\section{Unconfirmed Peer Disagreements}

Before moving to unconfirmed superiority disagreements, it will be helpful to consider some of the major views in the literature on unconfirmed peer disagreements-disagreements where one lacks good reason to determine whether a disputant is a peer. Ben Sherman lays out two main camps on the epistemic significance of such disagreement.

Those in the first camp say that we should remain steadfast. Sherman calls the first view as "The Presumption in Favor of Self-Trust: we should trust our own judgment unless we have reason to think others' judgment is as good or better" (2015, p. 430). There are at least two possible views that fall into this camp.

SF1 In cases of unconfirmed peer disagreement, we should not take ourselves as epistemically superior, inferior or as peers, and we should just remain steadfast.

SF2 In cases of unconfirmed peer disagreement, we should just take ourselves as epistemically superior and hence remain steadfast. 
When we look at philosophers who fall into this camp, it is unclear which view they hold to. As mentioned above, Elga thinks that if one faces wide-ranging disagreement, then one has good reason to think one's disputant is not a peer and remain steadfast (2007, pp. 492-496). Similarly, Michael Thune argues that since atheists and theists will disagree on many religious propositions, both have good reasons not to take each other as peers and hence can remain steadfast (2010, p. 718). Lastly, David Christensen also seems to endorse this. Christensen considers the following skeptical principle: "Insofar as the dispute-independent evaluation fails to give me good reason for confidence that I'm better informed, or more likely to have reasoned from the evidence correctly, I must revise my belief in the direction of the other person's" (Christensen 2011, p. 15). This skeptical principle calls for skepticism as long as one has no good reason to privilege oneself, even if one lacks good reason to take another as a peer. Christensen thinks that we should reject this skeptical principle. Why think this? One reason is that the skeptical principle will lead to wholesale skepticism (Christensen 2011, pp. 15-16). Suppose you meet a global skeptic who disagrees with all your beliefs. Here, you would have no independent reason to take yourself as epistemically superior. If the skeptical principle were true, this would mean that you have to be skeptical of all your beliefs. But it is clear that meeting a global skeptic should not lead to wholesale skepticism. Hence, the skeptical principle should be rejected (Christensen 2011, pp. 15-16).

In contrast, the second camp calls for skepticism, endorsing some version of Christensen's skeptical principle. Once again, there are a few views that can fall under this camp.

S1 In cases of unconfirmed peer disagreement, we should not take ourselves as epistemically superior, inferior or as peers, and we should conciliate.

S2 In cases of unconfirmed peer disagreement, we should just take ourselves as epistemic peers and hence conciliate.

John Pittard seems to be favorable to S1 (2014, p. 94). He however thinks that this is no threat to religious belief as he allows one to use partisan reasons to privilege oneself. Robert Mark Simpson seems to hold to S2. He says, "If I have no non-question-begging way to appraise the relative epistemic credentials of me and my opponent in relation to the subject at hand, and if [conciliationism] is correct, then I should bite the bullet and revise my beliefs about this subject towards the middle ground" (2013, p. 576). So Simpson seems to think that when we are unsure who is epistemically superior, we should take each other as peers and then skepticism should arise as in peer disagreement (2013, pp. 575-576).

S2 transforms cases of unconfirmed peer disagreement into cases of peer disagreement and then applies conciliationism to the case. Note that one might agree that we should take ourselves as peers but argue that we should not conciliate. A number of philosophers seem to hold to S2 but they are divided on what counts as a good reason to privilege oneself. For example, Richard Feldman seems to think that there must be agreement of who is epistemically superior in order to count as a good reason. He says: "If the atheists or the theists ... have any reasons for thinking that they themselves, rather than those on the other side, are the cognitive superiors in this case, then they can identify and discuss those reasons. And the result will be that the evidence shows that all should agree about who the experts are or the evidence will show that there is no good basis for determining who the experts are" (2007, p. 210).

Sherman calls Feldman's view "The Presumption of Peerhood: when we know of disagreement, we should presume others are our epistemic peers, until we find mutually recognizable evidence of epistemic superiority on one side or the other" $(2015$, p. 430). In short, this view says that when we lack agreement on our epistemic positions, then we should take our disputant as a peer. In contrast, Sherman's Earn-a-Spine view differs in allowing one to take oneself as epistemically superior if one has justifiable reason to do so, even if it is not mutually recognizable (2015, pp. 431-432).

What should we make of these views? Let's start with SF2. First, I think it is odd to take oneself as superior since one lacks reason to take oneself as superior. If we lack good reason to believe X, we ought not to believe X. Defenders of such a view might appeal to self-trust. This however does not give me reason to believe that I am in an epistemically superior position than my disputant. Trusting oneself does not mean that one can trust oneself more than another person. Defenders may instead appeal to the value of avoiding skepticism. While I agree with avoiding skepticism, this does not justify taking oneself as epistemically superior. It is unclear how the threat of skepticism gives me reason to believe that I am epistemically superior. One can embrace SF1 to avoid skepticism. So SF2 should be rejected.

Now consider S2. First, it is odd to assign peerhood when one lacks reason to take one's disputant as a peer. Once again, if we lack good reason to believe X, we ought not to believe X. One may object here and argue that we should take others as peers because humans are cognitively similar. Hence, we should trust others as much as we trust ourselves. This objection however has difficulties. Elizabeth Fricker argues there are asymmetries between people over time. She says that although "normal humans all have similar basic cognitive equipment," their reliability differs depending on "how they train it and subsequently employ it" (Fricker 2014, p. 190). Furthermore, in the case of religious disagreements, given the error theories and different religious epistemological views, it is easy to see that disputants 
are not cognitively similar. There is significant epistemic asymmetry. So $\mathrm{S} 2$ should be rejected.

Lastly, both SF2 and S2 lack intuitive support. When you first meet a stranger, you lack reason to take him as superior, inferior or a peer. Should you then just take yourself as superior or as a peer? Intuitively, it seems not. If I lack the reasons, I should just remain agnostic about it.

The main point I want to highlight in this section is that one should remain agnostic about one's epistemic position relative to a disputant when one lacks reasons to do otherwise. There might be grounds for conciliating or remaining steadfast apart from the presumption that others are our peers or inferiors or superiors. This is where I think SF1 and $\mathrm{S} 1$ go right. Due to lack of space I will not pursue SF1 and $\mathrm{S} 1$, but in the next section I defend a principle similar to SF1.

\section{Steadfastness in Unconfirmed Superiority Disagreements}

To recap, I have argued that many religious disagreements are neither peer disagreements, nor unconfirmed peer disagreements, nor disagreements in which we are justified in taking ourselves as superior. As argued above in Sect. 4, due to the epistemic asymmetry, we have good reason to think that we are not peers and that one of us is superior, though we lack good reason indicating who it is. Hence, these religious disagreements are cases of unconfirmed superiority disagreements.

In Sect. 5, I had argued that if we cannot tell how our disputant compares to us epistemically, then we should just be agnostic about our disputant's epistemic position relative to ours. What then is the epistemic significance of religious disagreements? If I have theistic experiences that provide prima facie justification for my theistic beliefs, can religious disagreement act as a defeater for the justification? Should such disagreement cause significant doubt? I think not. Similar to SF1, I want to argue for

SF3 In cases of unconfirmed superiority disagreements, we should not take ourselves as epistemically superior, inferior or as peers, and we should remain relatively steadfast.

By "relatively steadfast," I mean that one should still persist in one's belief, though a bit of reduction of confidence might be called for. In other words, one's credence should be slightly lowered.

In cases of unconfirmed superiority disagreements, all I know is that my disputant is possibly epistemically superior (and possibly inferior). It is hard to see how this would give me reason to significant doubt myself. If I knew my disputant was actually epistemically superior, this would call for significant doubt. But knowing that my disputant is possibly epistemically superior only tells me that there might possibly be reason to doubt, not that there actually is reason to doubt. $^{28}$

Consider the following case. Suppose you and a stranger are taking a math test. The teacher says that one of you is smarter. Now, you have reason to doubt the stranger is a peer, yet it is unclear who is epistemically superior. During an exam you calculate that the answer to the math question is 50 . You accidentally see that the stranger wrote 40 . Since one of you is epistemically superior but you lack reason indicating who it is, this is a case of unconfirmed superiority disagreement. Intuitively, it does not seem that this calls for significant doubt or skepticism. It is only a possibility that the stranger is epistemically superior. One may turn to a more familiar case. Imagine I have the experience of seeing a tree. My friend then tells me that there might possibly be evidence that I am a brain in a vat and the tree does not really exist. Does this call for significant doubt? It seems not. All I know is that it is just a mere possibility. Until he gives evidence to suggest that this is actually the case, the brain in a vat story does not do much and remains a possibility. Likewise, until we have reason to think that the disputant is actually superior, the disagreement does not do much. Now I do want to note that it is intuitive to think that the above cases call for a bit of reduction in credence as they alert us to the possibility of being wrong. This is why we should remain relatively steadfast in unconfirmed superiority disagreements.

One might not share such intuitions or one might not find this line of thought convincing. One might think that knowing that a disputant is possibly epistemically superior is sufficient to call for significant doubt. Even if I grant this, it does not follow that unconfirmed superiority disagreements should cause us to significantly doubt ourselves. If knowing that a disputant is possibly epistemically superior is relevant, then so is knowing that a disputant is possibly epistemically inferior. Knowing that a disputant is possibly epistemically inferior would give me reason not to doubt despite the disagreement. So, I would end up having reason to doubt and reason not to doubt. These reasons would cancel each other out. Hence, in cases of unconfirmed superiority disagreements, we should remain relatively steadfast.

\footnotetext{
${ }^{28}$ One reviewer raises an objection here. Since there is a possibility that the person is an epistemic superior, I should be uncertain whether I should doubt. If I am uncertain whether I should doubt, then I should doubt. In reply, I do not see why this is so. Given that I believe a proposition and have reasons for my belief, and I am uncertain whether there are good reasons to doubt, it does not seem that I should end up in doubt.
} 


\section{Conclusion}

Some philosophers think that religious disagreements call for religious skepticism or for us to revise our religious beliefs significantly. I think this is wrong in many cases of religious disagreements. I have argued for two standards of assessing whether or not disputants are peers. Applying these to some cases of religious disagreements, we can have good reasons to think disputants are not peers. Yet, we cannot simply take ourselves as superior. It is an open question whether we are epistemically superior or inferior compared to our disputant. This is hence a case of unconfirmed superiority. Sadly, philosophers working on the epistemology of disagreement have paid little attention to such cases. I argued that in such cases, the disagreement does not call for significant doubt, allowing parties to be justified in remaining relatively steadfast in holding to their belief. Hence, such cases of religious disagreements do not call for religious skepticism or for us to revise our religious beliefs significantly.

Acknowledgements I wish to acknowledge the funding for this project from Nanyang Technological University under the Undergraduate Research Experience on CAmpus (URECA) programme. For suggestions and comments, I like to thank Chris Suhler, Preston Greene, Adam Elga, Esther Goh, Andrew Loke, Max Deutsch, the participants at the Haifa Philosophy of Religion Conference 2018, the two anonymous reviewers at Topoi and also guest editors Pat Bondy and David Godden.

\section{Compliance with Ethical Standards}

Conflict of interest There is no conflict of interest of any kind.

Ethical Approval This article does not contain any studies with human participants or animals performed by the authors.

\section{References}

Bergmann M (2009) Rational disagreement after full disclosure. Episteme 6(3):336-353

Bergmann M (2015) Religious disagreement and rational demotion. In: Kvanvig J (ed) Oxford studies in philosophy of religion, Vol, 6. Oxford University Press, Oxford, pp 21-57

Bogardus T (2013) Disagreeing with the (religious) Skeptic. Int J Philos Relig 74(1):5-17

Christensen D (2011) Disagreement, question-begging, and epistemic self-criticism. Philos Imprint 11(6):1-22
DePoe J (2011) The significance of religious disagreement. In: Evans J, Heimbach D (eds) Taking christian moral thought seriously: the legitimacy of religious beliefs in the marketplace of ideas. B \& H Academic, Nashville, pp 79-120

Elga A (2007) Reflection disagreement. Nous 41(3):478-502

Elgin C (2010) Persistent disagreement. In: Feldman R, Warfield T (eds) Disagreement. Oxford University Press, Oxford, pp 53-68

Feldman R (2007) Reasonable religious disagreements. In: Antony L (ed) Philosophers without god: meditations on atheism and the secular life. Oxford University Press, Oxford, pp 194-214

Frances B (2015) Religious disagreement. In: Oppy G (ed) The Routledge handbook of contemporary philosophy of religion. Routledge, New York, pp 180-191

Fricker E (2014) Epistemic trust in oneself and others-an argument from analogy? In: Callahan L, O'Connor T (eds) Religious faith and intellectual virtue. Oxford University Press, Oxford, pp 174-203

Gelfert A (2011) Who is an epistemic peer? Logos Episteme 2(4):507-514

Kelly T (2005) The epistemic significance of disagreement. In: Gendler T, Hawthorne J (eds) Oxford studies in epistemology Vol, 1. Clarendon Press, Oxford, pp 167-197

King N (2012) Disagreement: what's the problem? or a good peer is hard to find. Res 85(2):249-272

Kraft J (2012) The epistemology of religious disagreement: a better understanding. Palgrave Macmillan, New York

Lackey J (2010) A justificationist view of disagreements epistemic significance. In: Haddock A, Millar A, Pritchard D (eds) Social epistemology. Oxford University Press, Oxford, pp 298-325

Lackey J (2014) Taking religious disagreements seriously. In: Callahan L, O'Connor T (eds) Religious faith and intellectual virtue. Oxford University Press, Oxford, pp 299-317

Matheson J (2015) The epistemic significance of disagreement. Palgrave Macmillan, New York

Matheson J (2017) Disagreement and the rationality of religious belief. https://www.academia.edu/21566676/Disagreement_and_the_ Rationality_of_Religious_Belief. Accessed 5 June 2018

Moser P (2010) The evidence for god: religious knowledge reexamined. Cambridge University Press, Cambridge

Oppy G (2010) Disagreement. Int J Philos Relig 68(1):183-199

Pittard J (2014) Conciliationism and religious disagreement. In: Bergmann M, Kain P (eds) Challenges to moral and religious belief: disagreement and evolution. Oxford University Press, Oxford, pp $80-100$

Plantinga A (2015) Knowledge and christian belief. William B. Eerdmans Publishing Company, Grand Rapids

Russell B (2017) The elusive god: reorienting religious epistemology. In: Notre dame philosophical reviews. http://ndpr.nd.edu/ news/24247-the-elusive-god-reorienting-religious-epistemolo gy/. Accessed 5 June 2018

Sherman B (2015) Unconfirmed peers and spinelessness. Can J Philos 45(4):425-444

Simpson R (2013) Epistemic peerhood and the epistemology of disagreement. Philos Stud 164(2):561-577

Thune M (2010) Religious belief and the epistemology of disagreement. Philosophy Compass 5(8):712-724 